\title{
SUPEROVULAÇÃO EM ÉGUAS DA RAÇA CRIOULA E QUARTO DE MILHA COM EXTRATO DE PITUITÁRIA EQUINA (EPE)
}

\section{SUPEROVULATORY PROTOCOL WITH EQUINE PITUITARY EXTRACT (EPE) IN MARES CRIOULA AND THE QUARTER HORSE}

\author{
Deise Keli Farias ${ }^{1}$ ORCID - http://orcid.org/0000-0002-6624-3895 \\ Silvério Bunn² ORCID - http://orcid.org/0000-0002-3433-6114 \\ Aimê de Medeiros Friso ${ }^{3}$ ORCID - http://orcid.org/0000-0001-8840-9844 \\ André Thaler Neto ${ }^{1}$ ORCID - http://orcid.org/0000-0003-4850-1341 \\ Alceu Mezzalira1 ORCID - http://orcid.org/0000-0002-2567-5288 \\ Maicon Gaissler Lorena Pinto ${ }^{4}$ ORCID - http://orcid.org/0000-0001-8515-4516 \\ Rodrigo Arruda de Oliveira ${ }^{5}$ ORCID - http://orcid.org/0000-0002-8267-9031 \\ Fabricio Desconsi Mozzaquatro $6^{*}$ ORCID - http://orcid.org/0000-0001-5220-6404 \\ ${ }^{1}$ Universidade do Estado de Santa Catarina, Lages, SC, Brasil. \\ ${ }^{2}$ Médico Veterinário Autônomo, Lages, SC, Brasil. \\ 3Universidade do Estado de São Paulo, Botucatu, SP, Brasil. \\ ${ }^{4}$ Empresa de Pesquisa Agropecuária e Extensão Rural de Santa Catarina, Lages, SC, Brasil. \\ 5Universidade de Brasília, Brasília, DF, Brasil. \\ 'Universidade Federal do Pampa, Uruguaiana,RS, Brasil. \\ *Autor para correspondência - fmozzaquatro@yahoo.com.br
}

\section{Resumo}

Este trabalho compara a resposta superovulatória de éguas doadoras de embriões das raças Quarto de Milha (QM) e Crioula, utilizando um protocolo com baixa dose de extrato de pituitária equina (EPE). Oito éguas QM e seis éguas Crioulas foram acompanhadas durante 3 ciclos estrais consecutivos, sendo que cada ciclo corresponde a um grupo. Grupo Controle - monitoramento do crescimento folicular até a ovulação; Grupo EPE - monitoramento ultrassonográfico até que os folículos atingissem cerca de $20 \mathrm{~mm}$ de diâmetro e, posteriormente, administração de $7 \mathrm{mg}$ de EPE, duas vezes ao dia, até a indução da ovulação com 2500UI de hCG; Grupo Pós-EPE - idem ao grupo controle. Os dados foram submetidos à análise de variância, utilizando o procedimento GLM do pacote estatístico SAS, sendo previamente testadas para normalidade dos resíduos, e as médias comparadas pelo teste de Tukey ao nível de 5\%. Nas éguas Crioulas tratadas com EPE houve um aumento no número de ovulações $(\mathrm{p}=0,0534)$, com média de $3,33 \pm 2,06$ quando comparadas aos grupos controle e pós-EPE e às éguas da raça $\mathrm{QM}(2,00 \pm 0,53)$. O tratamento com EPE na dose preconizada permitiu uma melhor resposta superovulatória e produção embrionária nas éguas Crioulas, quando comparadas com as éguas Quarto de Milha.

Palavras-chave: Equinos. Embrião. Superovulação. Transferência de embriões.

\begin{abstract}
This study compared the superovulatory response of embryos donor mares of Quarter Horse (QH) and Crioula using a protocol with low dose of equine pituitary extract (EPE). Eight QH mares and six Crioula mares were monitored during 3 consecutive estrous cycles, with each cycle corresponds
\end{abstract}


to a group. Control Group - monitoring of follicle growth up to the ovulation; EPE group - when the follicles reached $20 \mathrm{~mm}$ in diameter were administered $7 \mathrm{mg}$ EPE twice daily. When the follicles achieved a diameter $35 \mathrm{~mm}$, the ovulation was induced with 2500UI hCG; Post-EPE Group - idem to the control group. Data were analyzed using GLM procedure of the SAS statistical package. The variables were submitted to the Tukey's test and least square means adjusted for multiple comparisons using the Tukey-Kramer's test, with significance level of 5\%. Values are presented as mean \pm SD. In the Crioula mares treated with EPE, there was an increase in the number of ovulations $(p=0.0534)$ with a mean of $3.33 \pm 2.06$ ovulations when compared to the control and post-EPE groups, and mares QM. (2.00 \pm 0.53$)$. Treatment with EPE in the recommended dose allowed better superovulatory response and rate of embryo recovery in Crioula mares when compared to the QM mares

Keywords: Equine. Embryo. Superovulation. Embryo transfer.

Recebido em: 15 de setembro de 2015

Aceito em: 26 de fevereiro de 2019

\section{Introdução}

A raça Crioula tem se destacado, em especial no Brasil, devido à significativa expansão dos plantéis, apresentando animais de alta qualidade e elevado padrão zootécnico, o que reflete no valor de comercialização dos animais. A utilização de biotécnicas ligadas à reprodução na espécie equina ganhou espaço nas últimas décadas, tornando-se um importante nicho de trabalho para o médico veterinário. Com a liberação da ABCCC para o uso da inseminação artificial (IA) e da transferência de embriões (TE) em animais da raça Crioula, ocorreu um maior aumento na utilização dessas técnicas nos últimos anos.

A superovulação é uma ferramenta que pode ser utilizada para melhorar as taxas de recuperação embrionárias na TE. A utilização de protocolos superovulatórios em equinos esbarra em problemas conceituais, visto que muitas vezes os técnicos esperam que o processo superovulatório seja equiparado aos resultados obtidos em outras espécies, por exemplo na espécie bovina. Vários trabalhos já foram desenvolvidos $^{(1,2)}$ e comprovam que os protocolos superovulatórios nos moldes daqueles aplicados para bovinos são ineficientes.

O efeito da resposta ovariana é dose dependente, ou seja, o aumento da dose de EPE promove maior estímulo folicular. Em contrapartida, alguns trabalhos mostram que, quanto maior for o número de ovulações, menor é a taxa de recuperação embrionária por ovulação ${ }^{(3,4)}$. Pesquisadores têm se dedicado ao estudo dos fatores responsáveis pela baixa recuperação embrionária em éguas superovuladas e ao desenvolvimento de protocolos que driblem esses problemas, promovendo a estimulação moderada dos ovários. Os trabalhos científicos existentes referentes à raça Crioula são escassos. As raças Crioula e Quarto de Milha apresentam características bem definidas e distintas entre si, principalmente em tamanho e peso. Pesquisas avaliando o comportamento da raça Quarto de Milha frente a protocolos de superovulação e transferência de embriões já foram desenvolvidos ${ }^{(5)}$, mas na raça Crioula pouco se sabe sobre seu comportamento fisiológico frente a tais biotécnicas reprodutivas. Assim, o presente estudo teve por objetivo avaliar a resposta superovulatória de éguas Crioulas quando se utiliza um protocolo com dose reduzida de EPE e, ao mesmo tempo, comparar essa resposta àquelas obtidas nas éguas da raça QM. 


\section{Material e métodos}

O estudo foi realizado durante a estação reprodutiva de 2011/2012 e a estação reprodutiva de 2012/2013 (outubro a janeiro). Os animais pertenciam a duas propriedades da região da serra catarinense, distantes $90 \mathrm{~km}$ entre si, apresentando a mesma condição climática (clima subtropical). A respectiva latitude e longitude das propriedades estão descritas a seguir: Animais da raça Quarto de Milha (2750'35.73"'S

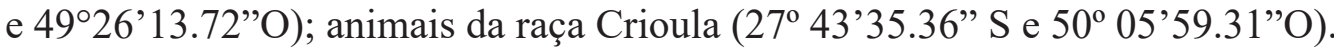

Foram utilizadas 8 éguas da raça Quarto de Milha e 6 éguas da raça Crioula. Os animais da raça Crioula apresentavam idades entre 3 e 4 anos, com média de peso de $345 \mathrm{~kg}$, e os animais da raça QM apresentavam idades variando de 3 a 11 anos, com média de peso de 532,5 kg. As fêmeas encontravam-se em pastagem de azevém e trevo durante o dia, com livre acesso à água e sal mineral. Durante a noite, permaneciam em cocheiras, recebendo suplementação com alfafa, aveia e ração comercial. As doadoras selecionadas apresentavam aparelho reprodutivo saudável e estavam livres de doenças infectocontagiosas.

As éguas foram divididas em dois grandes grupos, fêmeas da raça QM e fêmeas da raça Crioula. Dentro de cada raça as éguas foram avaliadas por três ciclos estrais consecutivos, sendo que cada ciclo estral correspondeu a um grupo. O primeiro ciclo estral foi classificado como o grupo Controle; o segundo, o grupo EPE; e o terceiro, o grupo pós-EPE, sendo conduzidos da seguinte forma: Grupo Controle: aplicação de PGF2 $\alpha$ no sétimo dia (ovulação = D0) e acompanhamento do crescimento folicular diário até a próxima ovulação. Grupo EPE: aplicação de PGF2 $\alpha$ no D8 e acompanhamento do crescimento folicular diário. A partir do momento em que presenciamos folículos com cerca de 20 mm de diâmetro, foi realizada a administração de $7 \mathrm{mg}$ totais EPE (EPE-Laboratório de Reprodução Animal-Unicórnio-Brasília), via intramuscular, duas vezes ao dia, com intervalo de $12 \mathrm{~h}$. Quando a maioria dos folículos alcançava um diâmetro igual ou superior a $35 \mathrm{~mm}$, foi induzida a ovulação pela administração de 2500UI de hCG por via intravenosa. Grupo Pós-EPE: Aplicação de PGF2 $\alpha$ no D8 e acompanhamento diário da dinâmica folicular até a ovulação. O EPE utilizado durante todo o estudo em ambas as raças foi oriundo de uma mesma partida de fabricação (Laboratório de Reprodução Animal - Unicórnio /Brasília - Frasco-ampola 400mg).

O monitoramento reprodutivo consistiu no acompanhamento diário do crescimento folicular de todas as éguas pela palpação retal e exame ultrassonográfico. A ultrassonografia foi realizada com auxílio de ultrassom Aloka, modelo SSD-500 com transdutor linear de 5,0 MHZ. O acompanhamento ultrassonográfico foi realizado até o momento da ovulação, sendo registrado o tempo de crescimento dos folículos, a taxa de crescimento folicular, o tamanho dos folículos pré-ovulatórios e o número de ovulações.

As inseminações foram realizadas com sêmen fresco pertencente a garanhões em boas condições reprodutivas, com fertilidade comprovada. As éguas QM foram inseminadas com um garanhão da raça QM e as éguas Crioulas foram inseminadas com um garanhão da raça Crioula. As colheitas de sêmen foram realizadas com auxílio de uma vagina artificial, a dose inseminante utilizada foi de 1 bilhão de espermatozoides viáveis. Quando o avaliador não identificou a ovulação em até 48 horas após o procedimento, a inseminação foi repetida.

No oitavo dia após a ovulação foi realizada a coleta de embriões pelo método não cirúrgico transcervical, por meio de uma lavagem uterina em um sistema fechado. Foi utilizada uma sonda 
estéril de silicone calibre 32, equipada de três vias, acoplada a um filtro coletor para embriões. Foram utilizados 3 a 5 litros de solução de ringer lactato, previamente aquecidos a $35^{\circ} \mathrm{C}$, para cada coleta. A re-coleta era sempre realizada quando o embrião não era observado na primeira procura. Após a localização do embrião, este era lavado e classificado quanto ao estágio de desenvolvimento e grau de qualidade, conforme as normas estabelecidas pela Sociedade Internacional de Tecnologia de Embriões (IETS; 2009).

Os dados das variáveis contínuas foram submetidos à análise de variância utilizando o PROC GLM do pacote estatístico SAS ${ }^{\circ}$ (SAS INSTITUTE, 2002), sendo previamente testados para normalidade dos resíduos pelo teste de Shapiro Wilks. O modelo estatístico foi composto pelas variáveis independentes grupo, ano, raça, pela interação grupo*raça e égua aninhado em raça. Para a variável dependente taxa de crescimento foi incluída ao modelo a covariável número de ovulações. As médias foram comparadas pelo teste de Tukey ao nível de significância de 5\%. Os valores estão sendo apresentados como médias $\pm \mathrm{SD}$.

\section{Resultados e Discussão}

A taxa de crescimento folicular foi acompanhada a partir do momento da indução da luteólise (oitavo dia pós ovulação) até o momento em que foi constatada a ovulação. Os folículos demoraram mais para ovular na raça Crioula, em comparação com a raça QM (10,1 $\pm 2,3$ vs 7,7 $\pm 1,8$ dias; $\mathrm{p}<0,01$, respectivamente). Esse crescimento mais lento ficou evidente nas éguas do grupo EPE (Crioula: 11,3+1,9 dias; QM: 7,2+1,6 dias; $\mathrm{p}<0,05$; ver Tabela 1). Dimmick et al. ${ }^{(7)}$ avaliaram a dinâmica folicular e a duração do estro em éguas da raça Quarto de Milha e da raça Árabe. As fêmeas da raça Árabe apresentaram estro mais longo quando comparado com as éguas da raça QM $(6,2 \pm 0,4$ vs 4,9 $\pm 0,38$ dias, respectivamente). Esse tempo de crescimento folicular mais lento fez com que as éguas Crioulas recebessem mais aplicações hormonais do que as éguas QM. Esse fato pode ter influenciado de forma positiva na maturação folicular e qualidade dos oócitos produzidos, o que de certa forma explicaria a maior taxa de produção embrionária encontrada nas éguas Crioulas (ver Figura 1).

Tabela 1. Período de crescimento folicular (dias), a partir do momento da aplicação do luteolítico até a ovulação no grupo controle, EPE e pós-EPE na raça Crioula e Quarto de Milha

\begin{tabular}{lll} 
QM & CRIOULA & Valor de $p$ \\
\hline
\end{tabular}

$\begin{array}{cccc}\text { Controle } & 7,2 \pm 1,7 & 9,5 \pm 2,7 & \\ \text { EPE } & 7,2 \pm 1,6^{\mathrm{b}} & 11,3 \pm 1,9^{\mathrm{a}} & \mathbf{p}<\mathbf{0 , 0 5} \\ \text { Pós -EPE } & 8,8 \pm 2,1 & 9,6 \pm 2,3 & \\ \begin{array}{c}\text { Tempo de crescimento dos } \\ \text { folículos até a ovulação }\end{array} & 7,7 \pm 1,8^{\mathrm{b}} & 10,1 \pm 2,3^{\mathrm{a}} & \mathbf{p}<\mathbf{0 , 0 1}\end{array}$

A taxa média diária de crescimento folicular nas éguas Crioulas foi de 3,08; 2,39 e 2,89mm no ciclo Controle, EPE e Pós-EPE, respectivamente. Já nas éguas Quarto de Milha a taxa de crescimento folicular foi de 3,49; 2,87 e 3,35mm para os grupos Controle, EPE e Pós-EPE, respectivamente. Ginther et al. ${ }^{(8)}$ relatam que, a partir da divergência, o folículo pré-ovulatório cresce a uma taxa média diária de $3 \mathrm{~mm}$ e Machado ${ }^{(9)}$ observou uma taxa de crescimento folicular nos grupos tratados com EPE de 2,2mm/ dia. Os achados do presente trabalho, referente à taxa de crescimento folicular ( $\mathrm{mm} / \mathrm{dia})$ e o tempo de 
crescimento folicular até a ovulação (dias), considerando a comparação ciclo estral fisiológico e ciclo estral com manipulação hormonal com EPE, ainda não tinham sido descritos para a raça Crioula. Esses dados reforçam as diferenças fisiológicas entre as raças frente ao tratamento hormonal proposto. Ainda quando observado o diâmetro médio do folículo pré-ovulatório de ambas as raças, nota-se similaridade no tamanho do folículo pré-ovulatório $(37,6 \pm 2,39 \mathrm{~mm}$ de diâmetro nas éguas Crioulas e 35,9 $\pm 3,2 \mathrm{~mm}$ para as QM). Esse fato reforça ainda mais essa diferença fisiológica na dinâmica/taxa de crescimento folicular. Estudos mais aprofundados em dinâmica folicular devem ser realizados para esclarecer esse fato.
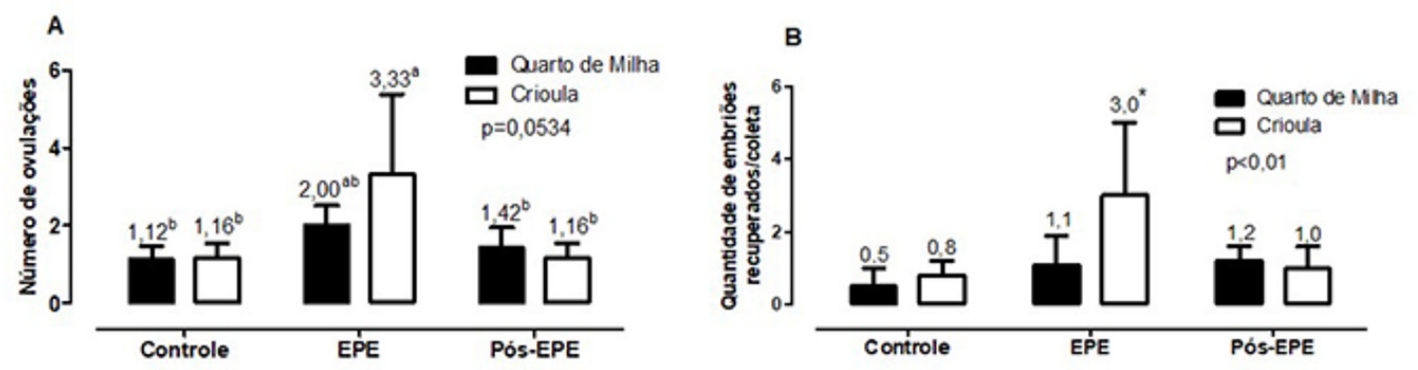

Figura 1. Quantidade média de folículos ovulados e embriões recuperados por égua nos diferentes grupos. A, Número de ovulações na raça Crioula e Quarto de Milha nos diferentes grupos ( ${ }^{a, b}$ demonstra diferença estatística tratamento versus raça; $\left.\mathrm{p}=0,0534\right)$. B, Número de embriões recuperados nas raças Crioula e Quarto de Milha nos diferentes grupos (* demonstra diferença estatística e interação entre tratamento e raça; $p<0,01$ ).

Os primeiros relatos no uso de FSH para indução de múltiplas ovulações em éguas utilizaram o FSH suíno (FSH-p), devido à sua ampla disponibilidade e eficácia na superovulação de bovinos. Porém, os resultados foram desanimadores, muito inferiores aos obtidos em vacas e de custo extremamente elevado. Ignácio et al. ${ }^{(1)}$ e Cullingford et al. ${ }^{(2)}$ testaram FSH-p em diferentes doses e verificaram que o hormônio foi ineficaz em induzir ovulações múltiplas em éguas. O extrato de pituitária equina (EPE) é um composto que apresentou relativo sucesso na superovulação ovariana em equinos. Os estudos com protocolos de superovulação em equinos focam na influência da dose diária de hormônio (EPE e/ ou FSHe) na resposta ovariana ${ }^{(4,10)}$. Esses trabalhos enfatizam que altas doses hormonais impactam positivamente o número de ovulações. No presente estudo foi verificado que, mesmo utilizando uma dose reduzida de EPE (14mg/dia), foi obtido um aumento do número de ovulações (Figura 1A $\mathrm{p}=0,05)$. Outra observação que os dados deste estudo proporcionam é que a resposta superovulatória nos equinos é variável e não só dependente da dose diária de EPE. Um conjunto de fatores, como raça, peso corporal, dose hormonal total administrada e, principalmente, velocidade de crescimento folicular também influenciaram na resposta superovulatória.

Os dados obtidos neste estudo mostram diferença entre as raças $(\mathrm{p}<0,05)$ no número de dias em tratamento com EPE, onde foram observadas médias de 6,6 0,6 e 4,7 0,7 dias para a raça Crioula e QM, respectivamente. Isso ocorreu devido à taxa de crescimento folicular diferenciada entre as raças, mais lenta nas Crioulas, em relação às QM, como mostrado nos dados acima. Rocha Filho ${ }^{(10)}$, utilizando EPE em éguas da raça Mangalarga, iniciou a aplicação do composto hormonal oito dias pós ovulação (D8), obtendo um tempo médio de tratamento com duração de 6,8 dias. Da mesma forma, Bonin et al. ${ }^{(5)}$ iniciou tratamento superovulatório com EPE, em éguas QM, no D8, e obteve tempo médio de tratamento de 9,4 dias. Os resultados aqui obtidos se diferenciam dos trabalhos citados, pois a metodologia para início do tratamento superovulatório foi diferente. $\mathrm{O}$ tratamento com 
EPE nas éguas só iniciou quando foram visualizados, através do ultrassom, folículos com diâmetro de $20 \mathrm{~mm}$ nos ovários.

Desta forma, por uma característica fisiológica da raça, as éguas Crioulas receberam uma dose total maior de hormônio, em média 92,4 mg de EPE, enquanto que as éguas QM receberam 65,8 mg de EPE por tratamento.

Outro fator também pesquisado neste trabalho foi a dose hormonal de EPE em relação ao peso corporal do animal nas diferentes raças. Mais uma vez, as éguas Crioulas (peso médio de $345 \mathrm{~kg}$ ) receberam uma dose maior de EPE do que as éguas QM (peso médio de 532,5 kg), quando o critério peso corporal foi levado em consideração.

Assim, o tratamento com EPE influenciou o número de ovulações nas diferentes raças ( $p=0,05$; Figura 1A). As éguas Crioulas do grupo EPE obtiveram 3,33 $\pm 2,06$ ovulações, quantidade superior à observada nos outros grupos, controle e Pós-EPE (1,16 $\pm 0,40$ ovulações cada). Já nas éguas da raça QM não foi observada diferença quanto ao número de ovulações $(1,12 \pm 0,35 ; 2,00 \pm 0,53 ; 1,42 \pm 0,53$, para os grupos controle, EPE e Pós-EPE, respectivamente).

O protocolo utilizando $7 \mathrm{mg}$ (b.i.d) de EPE mostrou-se eficiente em promover múltiplas ovulações, pois verificamos que $92,9 \%$ (13/14) das éguas responderam ao tratamento superovulatório. Bonin et al. ${ }^{(5)}$, ao superovularem éguas QM com peso entre 450 a $550 \mathrm{~kg}$ com dose de EPE semelhantes às utilizadas neste trabalho, obtiveram $65 \%$ (13/20) dos animais superovulados, com uma média de 1,8 ovulações por égua. Já Farinasso ${ }^{(11)}$ relata que 76,9\% (10/13) dos animais responderam ao tratamento superovulatório com dose de $6 \mathrm{mg}$ de EPE uma vez ao dia; e Rocha Filho ${ }^{(10)}$, utilizando $4 \mathrm{mg}$ de EPE uma vez ao dia, constatou uma resposta superovulatória de 30,8\% (4/13). Esta grande variabilidade nos resultados pode estar relacionada a uma série de fatores, dentre eles a dose, a frequência de tratamento e a presença de folículo dominante no início da superovulação. Outro aspecto que deve ser levado em conta é o fato de que há diferentes preparados hormonais, pois não se tem uma padronização do hormônio utilizado, ocorrendo provavelmente variação na proporção FSH:LH dos produtos utilizados. No presente estudo os autores tiveram o cuidado de utilizar a mesma partida em todo o experimento, assim a variabilidade nos resultados não aconteceu.

A grande incógnita no processo da superovulação na espécie equina tem sido a baixa taxa de recuperação embrionária. Squires \& $\mathrm{Mccue}^{(12)}$ relataram que, se a dose superovulatória for muito grande, o ovário torna-se excessivamente estimulado e muitos dos folículos não ovulam, luteinizando. Além disso, as características do ovário da égua (fossa de ovulação) e o infundíbulo (pequeno em relação ao ovário) parecem ser um impedimento anatômico que dificultam a captação dos oócitos ${ }^{(3,4)}$. Geralmente, se uma égua tem mais de cinco ovulações no mesmo ovário, a recuperação de embriões por ovulação é menor ${ }^{(10)}$.

Observamos que as éguas da raça $\mathrm{QM}(\mathrm{n}=8)$ que foram superovuladas apresentaram taxa de recuperação embrionária de 56,25\% (9 embriões/16 ovulações; 8 ciclos estrais). Nessa raça, a recuperação embrionária não foi influenciada $(\mathrm{p}<0,05)$ pelo tratamento com $E P E$, sendo recuperados $0,5 \pm 0,5$; $1,1 \pm 0,8$ e 1,2 $\pm 0,4$ embriões/ciclo nos grupos Controle, EPE e Pós-EPE, respectivamente. Esses dados estão de acordo com os obtidos por Bonin et al. ${ }^{(5)}$, que obtiveram taxa de recuperação embrionária de $60 \%$. Embora não tenha ocorrido diferença estatística na taxa de recuperação embrionária das éguas QM que receberam EPE em relação às do grupo controle, podemos observar que o número de embriões recuperados dobrou. Isso permitiu que pelo menos um embrião fosse recuperado por coleta.

Já nas éguas da raça Crioula $(n=6)$ que foram superovuladas, a taxa de recuperação embrionária foi de 90\% (18 embriões/ 20 ovulações; 6 ciclos estrais). O grupo EPE apresentou maior número 
de embriões recuperados em relação aos demais tratamentos $(3,0 \pm 2,0$ embriões/ciclo; $\mathrm{p}<0,01)$.

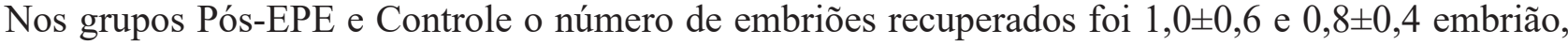
respectivamente (Figura 1B). Os dados obtidos no presente trabalho demonstraram que, com o uso de baixa dose hormonal, as taxas de recuperação embrionária aumentaram na raça Crioula quando comparamos com a raça $\mathrm{QM}$.

Os embriões coletados encontravam-se em estágio de blastocisto inicial, blastocisto e/ou blastocisto expandido, apresentando desenvolvimento condizente com o dia da ovulação e coleta. Ao avaliar a viabilidade e qualidade dos embriões recuperados, verificou-se que 90,4\% dos embriões foram classificados com grau 1, o restante $(9,6 \%)$ apresentava classificação de grau 2. Assim, o tratamento superovulatório não influenciou negativamente na qualidade dos embriões coletados. Outra informação relevante obtida é que não foi observada influência do ano/estação de monta, bem como variações climáticas em nenhuma das variáveis avaliadas $(\mathrm{p}>0,05)$.

\section{Conclusões}

Desta forma, podemos concluir que a taxa de crescimento folicular observada nos animais tratados com EPE foi similar à dos animais não tratados dentro de cada raça, aproximando-se das condições fisiológicas. As éguas Crioulas apresentaram uma taxa de crescimento folicular mais lenta comparado com os animais da raça QM, o que impactou positivamente na produção de embriões.

O tratamento com EPE na dose de $7 \mathrm{mg}$ b.i.d mostrou-se efetivo, aumentando a incidência de ovulações múltiplas nas éguas. Tal protocolo evidenciou uma melhor resposta superovulatória e taxa de recuperação embrionária nas éguas da raça Crioula quando comparado com as éguas da raça QM.

\section{Referências}

1. Ignácio FS, Bergfelt DR, Mendes D, Orlandi C, Araújo GH, Oliveira JV, et al. Ovarian response to porcine FSH in association with ablation-induced or spontaneous follicular wave development during the estrous cycle in cross bred and Brazilian Warm blood mares. Animal Reproduction Science. 2013; 137(1-2): 82-7. Doi: http://dx.doi.org/10.1016/j.anireprosci.2012.12.003.

2. Cullingford EL, Squires EL, Mccue PM, Seidel GE. Attempts at superovulation of mares with porcine follicle stimulating hormone and recombinant equine follicle stimulating hormone. Journal of Equine Veterinary Science. 2010; 30(6): 305-309. Doi: http://dx.doi.org/10.1016/j.jevs.2010.04.006.

3. Alvarenga MA, Mccue PM, Bruemmer J, Neves Neto JR, Squires EL. Ovarian superstimulatory response and embryo production in mares treated with equine pituitary extract twice daily. Theriogenology. 2001; 56: 879-687. Doi: http://doi.org/10.1016/S0093-691X(01)00615-X.

4. Carmo MT, Losinno L, Aquilar JJ, Araujo GHM, Alvarenga MA. Oocyte transport to the oviduct of superovulated mares. Animal Reproduction Science. 2006; 94:337-339. Doi:http://dx.doi.org/10.1016/j. anireprosci.2006.03.080.

5. Bonin BF, Dell'Aqua Júnior JA, Fioratti EG, Alvarenga MA. Efeito do tratamento com extrato de pituitária equina na resposta ovariana e eficiência de éguas idosas em programa de transferência de embriões. Veterinária e Zootecnia. 2010; 17(1): 94-103.

6. IETS. Manual da Sociedade Internacional de Transferência de Embriões. $4^{\text {a }}$ Edição. Illinois: IETS; 2009, 
$175 \mathrm{p}$.

7. Dimmick MA, Gimenez T, Schlanger RL. Ovarian follicular dynamics and duration of estrus and diestrus in Arabian vs. Quarter Horse mares. Animal Reproduction Science. 1993; 31: 123- 129. doi: http://dx.doi. org/10.1016/0378-4320(93)90032-M.

8. Ginther OJ, Gastal EL, Gastal MO, Beg MA. Dynamics of the equine preovulatory follicle and periovulatory hormones: what's new? Journal of Equine Veterinary Science. 2008; 28: 454-460. doi: http://dx.doi. org/10.1016/j.jevs.2008.07.008.

9. Machado MS. Avaliação da dinâmica folicular em éguas superovuladas com extrato de pituitária equina e FSH equino purificado [Dissertação] Botucatu (SP): Universidade Estadual Paulista, Faculdade de Medicina Veterinária e Zootecnia. 2004; http://hdl.handle.net/11449/98269.

10. Rocha filho AN. Efeito do tratamento com baixa dose de extrato de pituitária ou FSH purificado eqüino no crescimento folicular, taxa de ovulação e recuperação embrionária em éguas [Dissertação] Botucatu (SP): Universidade Estadual Paulista, Faculdade de Medicina Veterinária e Zootecnia. 2005; http://hdl.handle. net/11449/98223.

11. Farinasso A. Utilização de baixas doses de extrato de pituitária equina na indução de ovulações múltiplas em éguas cíclicas [Dissertação] Brasília:Universidade de Brasília; 2004.

12. Squires EL, Mccue PM. Superovulation in mares. Animal Reproduction Science. 2007; 99: 1-8. Doi: http://dx.doi.org/10.1016/j.anireprosci.2006.04.054. 